\title{
Awareness and Preferred Mode of Getting Information on First Aid Management of Avulsed Permanent Teeth: Survey of Nigerian Mothers
}

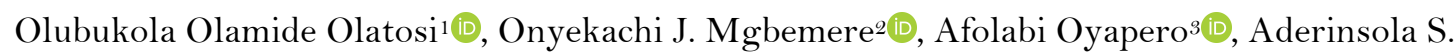 \\ Omotuyole1@, Chizoba C. Okolo+(i)
}

\begin{abstract}
'Department of Child Dental Health, Faculty of Dental Sciences, College of Medicine, University of Lagos, Lagos, Nigeria. ${ }^{2}$ Department of Preventive Dentistry, Lagos University Teaching Hospital, Lagos, Nigeria.

${ }^{3}$ Department of Preventive Dentistry, Faculty of Dentistry, Lagos State University College of Medicine, Lagos, Nigeria. ${ }^{4}$ Department of Child Dental Health, Aminu Kano Teaching Hospital, Kano, Nigeria.
\end{abstract}

Correspondence: Dr. Olubukola Olatosi, Department of Child Dental Health, Faculty of Dental Sciences, College of Medicine, University of Lagos, Nigeria. E-mail: bukkyolatosi@gmail.com

Academic Editor: Catarina Ribeiro Barros de Alencar

Received: 08 June 2020 / Review: 03 July 2020 / Accepted: 02 August 2020

\begin{abstract}
Objective: To determine the awareness and sources of information on first aid management of avulsed permanent teeth in a group of South-western Nigerian mothers. Material and Methods: An 18-item interviewer-administered questionnaire was used to survey 385 mothers attending the antenatal and immunization clinics on their perception towards dental avulsion, its management, sources, and preferred mode of receiving information on first aid. The effect of all significant factors was inferred at $\mathrm{p}<0.05$. Results: Mothers who had previous information on the first aid management of dental avulsion had significantly higher knowledge $(\mathrm{p}=0.000)$. Majority $(80.8 \%)$ of the mothers did not know that an avulsed permanent tooth could be replanted, though mothers whose children had not experienced dental trauma had significantly higher knowledge $(\mathrm{p}=0.003)$. The knowledge of first aid management of avulsed permanent tooth was low, regardless of age, education and employment status of the respondents. Conclusion: There was low knowledge among mothers regarding the first aid measures in the management of avulsed permanent teeth. Their main preference for receiving information was through social media and television. There is a need to increase oral health educational campaigns targeted towards mothers.
\end{abstract}

Keywords: Tooth Injuries; Tooth Avulsion; Tooth Fractures; First Aid. 


\section{Introduction}

Dental avulsion is the most serious form of traumatic dental injury and it is defined as the complete removal of a tooth out of its socket after the periodontal ligament is severed with or without fracture of the alveolar bone [1]. Avulsions constitute $0.5-16 \%$ of all traumatic dental injuries to permanent anterior teeth [2,3], while the teeth most commonly avulsed in the primary and permanent dentitions are the maxillary incisors [4]. These anterior teeth are important for aesthetics, mastication, speech, integrity of supporting tissues, and psychological and mental well-being of children [5,6]. Tooth avulsion is three times more frequent in boys than girls because of their active participation in sports, and it occurs most commonly from ages 7 to 9 years, when the permanent incisors are erupting [7]. Tooth avulsion can create significant psychosocial and economic problems for the child and the parents.

The loss of the permanent anterior teeth can be very distressing to both child and parents, and this can cause poor facial esthetics and may result in a child exhibiting low self-esteem $[7,8]$. However, an avulsed permanent tooth tends to heal and be retained for life if properly replanted, even though the prognosis of healing depends on appropriate emergency management immediately after the avulsion occurs [9,10]. Furthermore, since most dental injuries occur in the home environment, mothers who play a major role in the child's upbringing have a higher likelihood to handle an avulsed tooth than other persons. Therefore, it is pertinent to assess maternal knowledge on the important steps to take immediately dental avulsion occurs and design appropriate educational interventions to ensure successful outcomes of treatment [11,12].

Studies that have been conducted show a lack of knowledge among mothers and caregivers on the emergency management of traumatic dental injuries. In a study among teachers in Brazil, 91.2\% reported having no knowledge about the management of dental trauma, even though $16.6 \%$ of them had seen acute dental trauma cases. Regarding actions to take when acute injuries occur in permanent teeth, the teachers showed a significant error rate. The knowledge and actions of the Brazilian schoolteachers in relation to care of acute injuries in permanent teeth were inconsistent and based on unfounded concepts, beliefs and intuition, and lack of training [13]. In another study done in the United Arab Emirates, the level of knowledge about dental avulsion among mothers was inadequate, necessitating educational campaigns to improve the emergency management of dental injuries [14]. Similarly, in a Kuwaiti study, no difference was found in paternal and maternal knowledge about dental avulsion, and despite a high level of knowledge about the management of simple body injuries, knowledge about first aid management for dental injuries due to trauma was inadequate [10]. Furthermore, a study done in Lagos, Nigeria, to assess parental awareness of emergency management of avulsion of permanent teeth of children showed that a majority of the parents had little or no knowledge of what to do regarding emergency management of dental trauma [15].

Studies have been conducted among school teachers in Nigeria and also among parents to assess awareness of emergency management of dental trauma [15-17], but there is a paucity of data with regards to awareness of mothers and their preferred mode of receiving training on the first aid management of avulsion. Therefore, the purpose of this study was to determine the awareness and preferred mode of getting information on first aid management of avulsed permanent teeth in a group of South-Western Nigerian mothers.

\section{Material and Methods}

Ethics

Ethical approval for the study was obtained from the Health Research Ethics Committee of the Lagos University Teaching Hospital, Lagos, Nigeria, on the 9th of October 2019 (Protocol Number: 
ADM/DCST/HREC/APP/3240). Adequate consideration was given to protect the study participants' identity, and the confidentiality of the information given was guaranteed.

\section{Study Design and Population}

This was a cross-sectional descriptive study. The study was carried out at the Lagos University Teaching Hospital (LUTH), a teaching hospital located in Idi-Araba, Surulere, Lagos, Nigeria. Patients with diverse ethnicities, languages, cultures, and religions from Lagos and its environs are usually referred to LUTH. The study included mothers attending the antenatal clinic and those who brought their children to the LUTH immunization clinics.

\section{Sampling Method}

The sample included all mothers who were enrolled at the antenatal clinic and those who had their babies enrolled at the immunisation clinic at the Lagos University Teaching Hospital, Idi-Araba, Lagos, during the period of study. A simple random sampling technique using the balloting method was used for enlisting the study subjects using the attendance register for each clinic day as the sampling frame.

\section{Sample Size Determination}

The sample size was determined using a formula for a descriptive cross-sectional study. Sample size $=$ Z2 pq/e2, where $Z=1.96, p=$ with $16.7 \%$ prevalence of traumatic dental injuries in Lagos [18], q $=1-p$, with margin of error (e) set at 5\%. The minimum calculated sample size was 213 .

\section{Inclusion and Exclusion Criteria}

Those included were mothers attending the antenatal clinic and immunization clinic who had at least one child above the age of 6 years. The subjects were included in the study after explaining the study's nature to them and obtaining their informed consent. Mothers who were unwilling to give their informed consent and those who were unable to communicate were excluded from the study.

\section{Data Collection}

An 18-item structured, interviewer-administered questionnaire was used for data collection. This questionnaire was adapted from a previously validated questionnaire [16], which consisted of three main parts. The first part included the study participants' personal information (age, educational level, qualification, tribe and employment status). The second part explored the knowledge of the participants on the first aid management of an avulsed permanent tooth while the third part assessed the participants' source of information and willingness to receive more information and their preferred medium for receiving information on first aid management of avulsed teeth.

The right responses were assigned a score of 1, while wrong responses were given a score of 0 . The respondents were categorized as having either 'good' or 'poor' knowledge on the first aid management of avulsed permanent teeth and dental trauma based on their responses to the 8 knowledge questions. Obtaining a score $<4$ was classified as 'poor', and score $\geq 4$ as 'good' knowledge.

Data Analysis 
The data was analyzed using IBM SPSS software version 23.0 (IBM Corporation, Armonk, NY, USA). Frequency tables were made for all variables, and central tendency and dispersion measures were computed for numerical variables. Descriptive statistics, including means, standard deviations, and percentages, were used to present the socio-demographic variables and knowledge of the study population. The chi-square test was used to determine the level of association between variables. Differences and associations were considered statistically significant, where the associated p-values were equal to or less than 0.05.

\section{Results}

A total of 385 mothers participated in the study with a mean age of $33.6 \pm 6.4$ years. The majority of the mothers $(64.2 \%)$ had tertiary education and $39.2 \%$ had full-time employment. About a third of the mothers stated that their children had experienced dental trauma. Fractured anterior tooth was the most common type of traumatic dental injury (53\%), followed by avulsion (16\%) and jaw fracture $(3 \%)$.

Table 1 shows the participants' knowledge on the first aid management of an avulsed permanent tooth. When asked about the immediate response to dental trauma in a child, more than half (65.4\%) of the mothers reported that they will take the child to the dentist, while $26.5 \%$ of them stated that they will manage child and self-administer medication. A high proportion (80.8\%) of the mothers did not know that an avulsed permanent tooth could be replanted. A greater proportion $(64.7 \%)$ of the mothers stated they will not keep an avulsed permanent tooth if found. Of the 136 mothers who stated that they will keep it, $75.7 \%$ opted to take the avulsed permanent tooth along with the child to the dentist.

On the transport media for an avulsed permanent tooth, most mothers (74.3\%) reported they will use paper/gauze/plastic bag while $11.0 \%$ chose milk as the preferred transport medium. Most of the mothers $(65.7 \%)$ answered correctly that professional dental care should be sought immediately or within an hour of having experienced an avulsed tooth. Two hundred and two $(60.3 \%)$ of the mothers agreed that tetanus toxoid is important in the first aid management of dental trauma. After scoring the respondents on their first aid knowledge of the management of an avulsed permanent tooth, less than half $(46.8 \%)$ of the mothers had good knowledge of the first aid management of an avulsed permanent tooth.

Table 1. Mothers' knowledge on first aid management of an avulsed permanent tooth.

\begin{tabular}{lcc}
\multicolumn{1}{c}{ Variables } & N & $\%$ \\
\hline Immediate Response/Care in Case of Trauma to the Teeth & 252 & 65.4 \\
Take Child to the Dentist & 102 & 26.5 \\
Give Self-Medication and Put Child to Rest & 13 & 3.4 \\
No Need for Treatment & 18 & 4.7 \\
Others & 74 & 19.2 \\
Are You Aware That an Avulsed Tooth can be Replanted/Put Back in Place? & 30.8 \\
Yes & 311 & 35.3 \\
No & 136 & 34.7 \\
Will You Keep an Avulsed Tooth if Found? & 249 \\
Yes & 103 & 75.7 \\
No & 30 & 22.1 \\
An Avulsed Tooth Should be Taken to the Dentist Along with the Child & 3 & 2.2 \\
Yes & & \\
No & 101 & 74.3 \\
I Don't Know & 15 & 11.0 \\
How Should the Avulsed Tooth be Kept When Going to the Dentist & 15 & 11.0 \\
Paper/Tissue/Gauze/Plastic Bag & & \\
Milk & &
\end{tabular}


Saline $\quad \begin{array}{rr}4 & 3.0\end{array}$

Others

$\begin{array}{ll}1 & 0.7\end{array}$

How Soon do You Think it is Appropriate to Seek Professional Help for an Avulsed Tooth?

Immediately/Within an Hour

Within a Few Hours

At Least Before the Next Day

When There is Pain

\section{3}

65.7

$35 \quad 9.1$

I Don't Know

$9 \quad 2.3$

$48 \quad 12.5$

Administration of Tetanus Toxoid is Important in Management of Dental Trauma

Yes

No

I Don't Know

359.1

It is Important to Seek Professional Dental Care as Regard Dental Trauma

Yes

$\mathrm{No}$

ummary of Knowledge of Participants

Good Knowledge

Poor Knowledge

In Table 2, the respondents' source and preferred mode of receiving information/training on first aid management of dental avulsion is shown. Three hundred and four (79\%) of the mothers had not received any form of information with regards to first aid management of dental avulsion. Of those 81 (21\%) that had received information on first aid management of dental avulsion, 9.9\% got their information from the dental clinic/hospital followed by television (4.9\%) and from family/friends (4.4\%). Almost all the mothers (96.4\%) were willing to receive more information on first aid management of dental avulsion. When asked about their preferred medium of receiving information, most of the mothers (49\%), chose social media platforms, followed by television/radio $(43.9 \%)$.

Table 2. Mothers' source of and preferred mode of receiving information/training on first aid management of dental trauma.

\begin{tabular}{|c|c|c|}
\hline Variables & $\mathbf{N}$ & $\%$ \\
\hline \multicolumn{3}{|c|}{ Ever Received Information on First Aid Management of Dental Trauma in Children } \\
\hline Yes & 81 & 21.0 \\
\hline No & 304 & 79.0 \\
\hline \multicolumn{3}{|l|}{ Source of Information } \\
\hline Television or Radio Show & 19 & 4.9 \\
\hline Social Media & 10 & 2.6 \\
\hline Books, Magazines and Newspapers & 7 & 1.8 \\
\hline Dental Clinic/Hospital & 38 & 9.9 \\
\hline Friends/Family & 17 & 4.4 \\
\hline School/Seminar & 2 & 0.5 \\
\hline \multicolumn{3}{|c|}{ Knowledge of First Aid Management of Dental Trauma is Sufficient } \\
\hline Yes & 91 & 23.6 \\
\hline No & 294 & 76.4 \\
\hline \multicolumn{3}{|c|}{ Willingness to Receive More Information on First Aid Management of Dental Trauma } \\
\hline Yes & 371 & 96.4 \\
\hline No & 14 & 3.6 \\
\hline \multicolumn{3}{|c|}{ Preferred Means of Receiving Information on First Aid Management of Dental Trauma } \\
\hline Television/ Radio Show & 169 & 43.9 \\
\hline Social Media & 189 & 49.1 \\
\hline Books, Magazines, Newspaper & 46 & 11.9 \\
\hline Clinic/Hospital & 35 & 9.1 \\
\hline Workshop/ Community Talk & 7 & 1.8 \\
\hline
\end{tabular}


Those whose children had not experienced dental trauma had significantly higher knowledge than those whose children had experienced dental trauma $(\mathrm{p}=0.003)$ and those from the Hausa tribe had significantly poorer knowledge than those of other tribes $(\mathrm{p}=0.000)$ (Table 3).

Table 3. Association between mothers' knowledge of first aid management of avulsed tooth and sociodemographics characteristics.

\begin{tabular}{|c|c|c|c|c|c|}
\hline \multirow[b]{2}{*}{ Socio-Demographics Characteristics } & \multicolumn{2}{|c|}{ Frequency } & \multicolumn{2}{|c|}{ Knowledge } & \multirow[b]{2}{*}{ p-value } \\
\hline & $\mathrm{N}$ & $\%$ & $\begin{array}{l}\text { Good } \\
\text { N (\%) }\end{array}$ & $\begin{array}{l}\text { Poor } \\
\text { N (\%) }\end{array}$ & \\
\hline \multicolumn{6}{|l|}{ Age (Years) } \\
\hline $20-29$ & 97 & 25.2 & $37(38.1)$ & $60(61.9)$ & 0.225 \\
\hline $30-39$ & 219 & 56.9 & $107(48.9)$ & $112(51.1)$ & \\
\hline $40-49$ & 62 & 16.1 & $33(53.2)$ & $29(46.8)$ & \\
\hline$\geq 50$ & 7 & 1.8 & $3(42.9)$ & $4(57.1)$ & \\
\hline \multicolumn{6}{|l|}{ Mean Age $=33.6 \pm 6.4$ years } \\
\hline \multicolumn{6}{|l|}{ Educational Level } \\
\hline Primary & 22 & 5.7 & $7(31.8)$ & $15(68.2)$ & 0.108 \\
\hline Secondary & 98 & 25.5 & $37(37.8)$ & $61(62.2)$ & \\
\hline Tertiary & 247 & 64.2 & $126(51.0)$ & $121(49.0)$ & \\
\hline No Formal Education & 18 & 4.6 & $10(55.6)$ & $8(44.4)$ & \\
\hline \multicolumn{6}{|l|}{ Employment Status } \\
\hline Working (Full-Time) & 151 & 39.2 & $70(46.4)$ & $81(53.6)$ & 0.236 \\
\hline Working (Part Time) & 110 & 28.6 & $59(53.6)$ & $51(46.4)$ & \\
\hline Student & 18 & 4.7 & $9(50.0)$ & $9(50.0)$ & \\
\hline Not Working & 106 & 27.5 & $42(39.6)$ & $64(60.4)$ & \\
\hline \multicolumn{6}{|l|}{ Tribe } \\
\hline Igbo & 150 & 39.0 & $68(45.3)$ & $82(54.7)$ & 0.0002 \\
\hline Hausa & 11 & 2.9 & $\mathrm{O}(0.0)$ & $11(100.0)$ & \\
\hline Yoruba & 195 & 50.6 & $90(46.2)$ & $105(53.8)$ & \\
\hline Others & 29 & 7.5 & $22(75.9)$ & $7(24.1)$ & \\
\hline \multicolumn{6}{|l|}{ Ever Encountered any Case of Dental Trauma in a Child } \\
\hline Yes & 127 & 33.0 & $47(26.1)$ & $80(39.0)$ & 0.003 \\
\hline No & 258 & 67.0 & $133(73.9)$ & $125(61.0)$ & \\
\hline \multicolumn{6}{|c|}{ Previous Information on First Aid Management of Dental Trauma } \\
\hline Yes & 81 & 21.0 & $56(69.1)$ & $25(30.9)$ & 0.000 \\
\hline No & 304 & 79.0 & $124(40.8)$ & $180(59.2)$ & \\
\hline
\end{tabular}

Those mothers who had previous information on the first aid management of dental trauma had significantly higher knowledge than those who had not $(\mathrm{p}=0.000)$.

\section{Discussion}

Our study assessed mothers' knowledge on first aid management of avulsed permanent teeth and their preferred mode of receiving information on emergency management of dental trauma. The loss of the permanent anterior teeth can be very distressing to both child and parents, while poor aesthetics resulting from the loss can cause a child to exhibit low self-esteem [7,8]. Even though most of the mothers from the present study had tertiary education, the highest proportion of respondents had poor knowledge on the immediate management of an avulsed tooth. This resulted from lack of awareness because most (79\%) of the mothers had never received any information or training on first aid management of dental trauma. This was similar to other studies $[7,12,15,19,20]$ where they reported poor awareness regarding first aid management of dental trauma, indicating that literacy may not automatically translate into health literacy.

One significant finding in this study is the method through which information is disseminated to mothers/caregivers. When the mothers were asked about their source of information on dental emergencies 
most of them reported that they had received their information from the dental clinic/hospital. Similarly, when the mothers were asked about their preferred mode of receiving information most chose social media, which is different from the hospital setting. This was in agreement with a similar study, conducted in Saudi Arabia [21]. Most often, mothers/caregivers get information on prevention and first aid management of dental trauma at the dental clinic after the incidence has occurred. Patients seek professional help often times for curative rather than preventive purposes [22]. This knowledge should make researchers and clinicians seek for innovative and patient-friendly ways to get evidence-based information out in a timely and effective manner and to those who need it the most, beyond the dental clinic settings. It is important to consider patients' preferred mode of receiving information because this could help when planning health education for mothers and their children. In this era of the widespread use of various social media platforms, social media has become a trusted source of information to many people, and it may be worthwhile to use it as one of the channels of dental public health enlightenment.

From our study, only $19 \%$ of mothers knew that an avulsed tooth could be replanted. This finding was higher than that reported by Murali et al. [20] (7\%), but lower than that reported by Oliveira et al. [23] (39\%), Loo et al. [7] (43.3\%), Raphael and Gregory [24] (66.6\%), and Hegde et al. [25] (66.5\%). Ignorance about the management of an avulsed tooth could lead to the tooth being thrown away or abandoned at the site of accident. Similarly, only $35 \%$ of the mothers stated they will keep an avulsed tooth, of which the higher proportion opted to transfer it in the wrong storage media (paper or gauze). This corroborates the findings by similar studies $[7,12,19,20]$ where they reported poor knowledge about transport media choice. Dry storage of the tooth in media such as plastic bags, paper, handkerchiefs will allow irreversible desiccation of the periodontal ligament, resulting in the loss of the replanted tooth over time [9,26]. Mothers whose children had not experienced dental trauma had significantly higher knowledge than those whose children had experienced dental trauma. This may be an indication that maternal knowledge about dental trauma was translated into preventive practices but we cannot make causal inferences because of the descriptive nature of our study.

Emergency management of an avulsed permanent tooth involves keeping the patient calm; if the tooth is found, it should be picked by the crown, rinsed under running water, and replanted in the socket. When this is not possible, the tooth should be placed in a storage medium and brought to the clinic with the patient for replantation. Maintaining an avulsed tooth in a suitable wet storage medium, which can preserve the tooth's vitality, is key to a successful replantation [27]. The ideal storage medium should be capable of preserving cell vitality, adherence and clonogenic capacity [28] and should be readily available at the site of the accident or easily accessible. A recent literature review showed that several types of wet storage media have been evaluated in laboratory studies and clinical reports: these include bovine milk, saliva, egg white, coconut water, green tea, and tissue culture solutions such as Hank's Balance Salt Solution. They concluded that apart from solutions designed specifically for storage and culture purposes, regular pasteurized whole milk was the most frequently recommended medium with the best prognosis due to its ready availability, easy access, physically compatible $\mathrm{pH}$, and the presence of nutrients and growth factors [28].

A good number of the mothers (65\%) agreed that professional care should be sought immediately a permanent tooth is avulsed. Previous authors concluded that under any circumstance, best results will be achieved if the tooth remains out the socket for less than 20 minutes [29]. In contrast, other authors have shown that appropriate replantation of an avulsed permanent tooth within 30 minutes has a $90 \%$ chance of 
success [30]. Only a negligible chance (5\%) of long-term retention of an avulsed tooth exists if replantation occurs after two hours [30].

It is worth noting that most mothers $(71 \%)$ from the present study had not received information on first aid management of dental trauma. This finding, though still portraying inadequate knowledge, shows that there has been a marginal improvement in information dissemination when compared to a similar study conducted in Nigeria over a decade ago, which reported that (91\%) of the parents had never received information [15]. This present study also revealed that those mothers who had received previous information on first aid management of dental trauma had significantly higher knowledge than those who had not. There is still a need for more educational campaigns directed towards the first aid management of dental trauma as most of the campaigns are targeted towards prevention of caries and other oral diseases.

Within the limit of our study, the knowledge of first aid management of avulsed permanent teeth was low, regardless of age, education and employment status. Mothers with previous information on management of dental trauma had significantly higher knowledge. Evidence from a systematic review shows that children and adolescents whose traumatic dental injuries (TDI) have no associated complications have similar quality of life with children without injuries [31]. Research has also shown that instituting measures that promote healthy practices lead to a lower prevalence of TDI [32]. Hence, there is a need for continuous oral health campaign targeted towards prevention and emergency management of dental trauma using the appropriate and preferred means. Future randomized population-based interventional studies to improve maternal knowledge on first aid management of dental trauma are recommended.

\section{Conclusion}

Maternal knowledge about the first aid management of avulsed permanent teeth in Nigeria was low, regardless of age, educational level, and working status. The mothers' preference for receiving information/training was through social media and television. There is a need to increase oral health educational campaigns targeted towards mothers, utilising their preferred mode of receiving the information.

\section{Authors' Contributions}

\begin{tabular}{|c|c|c|}
\hline OOO & (D) https://orcid.org/0000-0003-1395-8261 & $\begin{array}{l}\text { Conceptualization, Methodology, Formal Analysis, Writing - Original Draft Preparation and } \\
\text { Writing - Review and Editing. }\end{array}$ \\
\hline OJM & (D) https://orcid.org/0000-0002-1 104-0150 & $\begin{array}{l}\text { Conceptualization, Methodology, Formal Analysis, Writing - Original Draft Preparation and } \\
\text { Writing - Review and Editing. }\end{array}$ \\
\hline $\mathrm{AO}$ & (D) https://orcid.org/0000-0003-4433-8276 & $\begin{array}{l}\text { Conceptualization, Methodology, Formal Analysis, Writing - Original Draft Preparation and } \\
\text { Writing - Review and Editing. }\end{array}$ \\
\hline ASO & https://orcid.org/0000-0003-0324-1144 & $\begin{array}{l}\text { Conceptualization, Methodology, Formal Analysis, Writing - Original Draft Preparation and } \\
\text { Writing - Review and Editing. }\end{array}$ \\
\hline $\mathrm{CCO}$ & https://orcid.org/0000-0002-0534-9792 & Conceptualization, Methodology, Formal Analysis and Writing - Original Draft Preparation. \\
\hline
\end{tabular}

\section{Financial Support}

None.

\section{Conflict of Interest}

The authors declare no conflicts of interest.

\section{Data Availability}

The data used to support the findings of this study can be made available upon request to the corresponding author.

\section{Acknowledgements}


The authors acknowledge the mothers who participated in the program as well as the Paediatric dentistry resident doctors, house officers and other facilitators who were involved in the study.

\section{References}

[1] Andreasen JO, Andreasen FM, Andersson L. Textbook and Colour Atlas of Traumatic Injuries to the Teeth. 4th ed. Oxford: Blackwell Munksgaard; 2007..

[2] Lygidakis NA, Marinou D, Katsaris N. Analysis of dental emergencies presenting to a community paediatric dentistry centre. Int J Paediatr Dent 1998; 8(3):181-90. https://doi.org/10.1046/j.1365-263x.1998.00079.x

[3] Saroglu I, Sonmez H. The prevalence of traumatic injuries treated in the pedodontic clinic of Ankara University, Turkey, during 18 months. Dent Traumatol. 2002; 18(6):299-303.

https://doi.org/10.1034/j.1600-9657.2002.00093.x

[4] Andreasen JO, Borum MK, Jacobsen HL, Andreasen FM. Replantation of 400 avulsed permanent incisors. 1. Diagnosis of healing complications. Endod Dent Traumatol 1995; 11(2):51-8.

https://doi.org/10.1111/j.1600-9657.1995.tbo0461.x

[5] Adekoya-Sofowora CA, Adesina OA, Nasir WO, Oginni AO, Ugboko VI. Prevalence and causes of fractured permanent incisors in 12 year-old suburban Nigerian school children. Dent Traumatol 2009; 25(3):314-7. https://doi.org/10.1111/j.1600-9657.2008.00704.x

[6] Adekoya-Sofowora CA, Bruimah R, Ogunbodede E. Traumatic dental injuries experience in surburban Nigerian adolescents. Internet J Dent Sci 2005; 3(1):1-6.

[7] Loo TJ, Gurunathan D, Somasundaram S. Knowledge and attitude of parents with regard to avulsed permanent tooth of their children and their emergency management-Chennai. J Indian Soc Pedod Prev Dent 2014; 32(2):97-107. https://doi.org/10.4103/0970-4388.130781

[8] Abdellatif AM, Hegazy SA. Knowledge of emergency management of avulsed teeth among a sample of Egyptian parents. J Adv Res 2011; 2(2):157-62. https://doi.org/10.1016/j.jare.2011.01.002

[9] Heithersay GS. Life cycles of traumatized teeth: long-term observations from a cohort of dental trauma victims series 2. Aust Dent J 2016; 61(3):317-28. https://doi.org/10.1111/adj.12430

[10] Al-Jame Q, Andersson L, Al-Asfour A. Kuwaiti parents' knowledge of first-aid measures of avulsion and replantation of teeth. Med Princ Pract 2007; 16(4):274-9. https://doi.org/10.1159/000102149

[11] Dua R, Sharma S. Prevalence, causes and correlates of traumatic dental injuries among seven-to-twelve-year-old school children in Dera Bassi. Contemp Clin Dent 2012; 3(1):38-41. https://doi.org/10.4103/0976-237X.94544

[12] Resmy N, Parvathy K, Arun XM, Balagopal V. Knowledge, attitude, and awareness of mothers toward emergency management of dental trauma in high literacy population. J Int Oral Health 2019;11:287-92.

[13] Antunes LAA, Rodrigues AS, Martins AMC, Cardoso ES, Homsi N, Antunes LS. Traumatic dental injury in permanent teeth: knowledge and management in a group of Brazilian school teachers. Dent Traumatol 2016; 32(4):269-73. https://doi.org/10.1111/edt.12249

[14] Hashim R. Investigation of mothers' knowledge of dental trauma management in United Arab Emirates. European Archives of Paediatric Dentistry. Eur Arch Paediatr Dent 2012; 13(2):83-6. https://doi.org/10.1007/BFo3262849

[15] Sanu OO, Utomi IL. Parental awareness of emergency management of avulsion of permanent teeth of children in Lagos, Nigeria. Niger Postgrad Med J 2005; 12(2):115-20.

[16] Olatosi OO, Iwuala SO, Isiekwe GI, Oredugba FA, Adenaike AS, Oluwo AO. Knowledge and attitude of some Nigerian school teachers on the emergency management of avulsed permanent incisor. J West Afr Coll Surg 2013; $3(4): 30-52$.

[17] Adekoya-Sofowora C, Oziegbe E, Ugboko V, Akinbade A. Knowledge of first aid measrures of avulsion and replantation of teeth in Nigerian school children. Internet J Dent Sci 2009; 7(1):1-7.

[18] Piponsuhu RA, Agbaje MO, Osisanya MO, Oyapero A. Pattern and treatment needs of traumatized anterior permanent teeth in a sub-urban area in Lagos State. Edorium J Dent 2016; 3:54-62.

[19] Jain A, Kulkarni P, Kumar S, Jain M. Knowledge and Attitude of Parents towards Avulsed Permanent Tooth of their Children and its Emergency Management in Bhopal City. J Clin Diagn Res 2017; 11(5):ZC40-ZC44. https://doi.org/10.7860/JCDR/2017/24953.9855

[20] Murali K, Krishnan R, Kumar VS, Shanmugam S, Rajasundharam P. Knowledge, attitude, and perception of mothers towards emergency management of dental trauma in Salem district, Tamil Nadu: a questionnaire study. J Indian Soc Pedod Prev Dent 2014; 32(3):202-6. https://doi.org/10.4103/0970-4388.135825

[21] Nourwali IM, Maddhar AK, Alsaati BH, Alhazmi RA, AlAyoubi SM, AlHarbi SS. Emergency management of dental trauma: a survey of public knowledge, awareness, and attitudes in Al-Madinah Al-Munawwarah. Clin Cosmet Investig Dent 2019; 11:279-84. https://doi.org/10.2147/CCIDE.S205248

[22] Olatosi OO, Onyejaka NK, Oyapero A, Ashaolu JF, Abe A. Age and reasons for first dental visit among children in Lagos, Nigeria. Niger Postgrad Med J 2019; 26(3):158-63. https://doi.org/10.4103/npmj.npmj_60_19

[23] Oliveira TM, Sakai VT, Moretti ABS, Silva TC, Santos CF, Machado MAAM. Knowledge and attitude of mothers with regards to emergency management of dental avulsion. J Dent Child 2007; 74(3):200-2. 
[24] Raphael SL, Gregory PJ. Parental awareness of the emergency management of avulsed teeth in children. Aust Dent J 1990; 35(2):130-3. https://doi.org/10.1111/j.1834-7819.1990.tb05878.x

[25] Hegde AM, Kumar KNP, Varghese E. Knowledge of dental trauma among mothers in Mangalore. Dent Traumatol 2010; 26(5):417-21. https://doi.org/10.1111/j.1600-9657.2010.00905.x

[26] Andreasen JO. Effect of extra-alveolar period and storage media upon periodontal and pulpal healing after replantation of mature permanent incisors in monkeys. Int $J$ Oral Surg 1981; 10(1):43-53. https://doi.org/10.1016/s0300-9785(81)80007-5

[27] Khinda VI, Kaur G, Brar GS, Kallar S, Khurana H. Clinical and practical implications of storage media used for tooth avulsion. Int J Clin Pediatr Dent 2017; 10(2):158-65. https://doi.org/10.5005/jp-journals-10005-1427

[28] Zhao Y, Gong Y. Knowledge of emergency management of avulsed teeth: A survey of dentists in Beijing, China. Dent Traumatol 2010; 26(3):281-4. https://doi.org/10.1111/j.1600-9657.2010.00877.x

[29] Andreasen JO, Hjorting-Hansen E. Replantation of teeth 1. Radiographic and clinical study of 110 human teeth replanted after accidental loss. Acta Odontol Scand 1966; 24(3):263-86. https://doi.org/10.3109/00016356609028222

[30] Lin S, Emodi O, EI-Naaj IA. Splinting of an injured tooth as part of emergency treatment. Dent Traumatol 2008; 24(3):370-2. https://doi.org/10.1111/j.1600-9657.2007.00530.x

[31] Silva-Oliveira F, Goursand D, Ferreira RC, Paiva PCP, Paiva HN, Ferreira EF, et al. Traumatic dental injuries in Brazilian children and oral health-related quality of life. Dent Traumatol. Dent Traumatol 2018; 34(1):28-35. https://doi.org/10.1111/edt.12358

[32] Quezada-Conde MDC, Alvarez-Velasco PL, Lopez EF, Medina MV, Marques RPS, Wanderley MT, et al. Influence of school environment on occurrence of traumatic dental injuries in 12 years old children. Dent Traumatol 2020; 36(5):510-7. https://doi.org/10.1111/edt.12559 